\title{
EVASÃO NA EDUCAÇÃO A DISTÂNCIA: UM ESTUDO DE CASO
}

Fátima Kzam Damaceno de Lacerda | fatima_kzam@yahoo.com.br Doutorado em Meio Ambiente pela Universidade do Estado do Rio de Janeiro (UERJ).

Professora Adjunta do Instituto de Química da UERJ. Diretora de Polo de Apoio presencial do CEDERJ/UAB.

Romário de Macedo Espíndola | romariome@hotmail.com

Licenciado em ciências biológicas pelo IBRAG/UERJ pelo Consórcio CEDERJ, no Polo de Nova Friburgo. Pesquisador nos cursos semipresenciais da UERJ no Polo EAD de Nova Friburgo. Cursa Medicina na UERJ.

\section{Resumo}

Este trabalho tem o objetivo de estudar os motivos de evasão no curso de Licenciatura em Ciências Biológicas do polo de educação a distância do Cederj/UAB localizado no município de Nova Friburgo-RJ. Com esse objetivo, foi realizado um estudo exploratório utilizando os dados contidos no sistema acadêmico do Cederj para obter o número de alunos evadidos das dez primeiras turmas do curso, de 2006 a 2011. Posteriormente, para estudar o motivo de os estudantes abandonarem o curso, foram realizadas entrevistas, por meio de ligações telefônicas, com 30 ex-alunos do curso. Os resultados indicaram que no grupo pesquisado ocorreu evasão de $43 \%$, que se concentrou nos três períodos iniciais do curso. Os principais motivos de evasão são relatados. Observou-se tendência de diminuição da evasão ao longo do tempo, o que pode estar relacionado com as ações de apoio acadêmico ao estudante que vêm sendo desenvolvidas pela instituição de ensino.

\section{Palavras-chave}

Educação a distância. Evasão em EaD. Formação de Professores. 
Dropout in distance education: a case study.

\section{Abstract}

This work aims to study the reasons for dropout in degree course in biological sciences at the polo of distance education CEDERJ/UAB located in Nova Friburgo-RJ. With this aim, we conducted a exploratory study using, initially, the data contained in the academic's system of CEDERJ to obtain the number of dropout students from the first ten classes of the course, from 2006 to 2011. Subsequently, to study why students leave the course, interviews were conducted via telephone calls, with 30 ex-students of the course. The results indicated that the group studied was an evasion of $43 \%$ which is focused on the three initial periods of the course. The main reasons for dropout are reporting. A tendency for decreasing of dropout was observed over time, which may be related to the actions of the student's academic support that has been developed by the educational institution.

\section{Keywords}

Distance education. Dropout in distance education. Teacher training.

\section{Introdução}

A Educação a Distância (EaD) não é uma modalidade de ensino recente. Desde a Antiguidade, correspondências eram usadas para a comunicação $e$ a transmissão de instruções (SARAIVA, 1996). Entretanto, com as novas tecnologias de informação e comunicação (NTICs), a EaD adquire grande potencial como ferramenta educacional, permitindo que haja interatividade e construção conjunta do conhecimento (SANTOS, 2009).

Com essas novas características, essa modalidade de ensino, se bem usada, pode trazer benefícios para o Brasil, que possui grandes dimensões e, historicamente, apresenta deficiências na área educativa.
Entre os benefícios possíveis, é notável o papel que a Educação a Distância pode assumir para levar cursos superiores para áreas afastadas dos grandes centros. Essas localidades muitas vezes sofrem com carência de trabalhadores qualificados, entre eles professores.

Estes profissionais têm enfrentado diversos desafios. Podem ser citadas, por exemplo, a má remuneração, as salas de aula lotadas, a desvalorização da profissão (FERREIRA, 2001). Além disso, na própria formação inicial os estudantes dos cursos de licenciatura vivenciam obstáculos a serem superados, como a necessidade de adquirir conhecimentos sólidos em áreas diversificadas e nem sempre de fácil assimilação (CARVALHO; GIL-PÉREZ, 2001).

Esses fatores contribuem para que poucos professores sejam formados. Um estudo feito pelo Instituto Nacional de Estudos e Pesquisas Educacionais Anísio Teixeira (Inep), em 2003, por exemplo, constatou que faltavam, naquele momento, 236 mil professores no Ensino Médio e 711 mil docentes para turmas do segundo ciclo do Ensino Fundamental. Além desse déficit, verifica-se que algumas vezes os futuros professores não se sentem preparados para enfrentar os desafios encontrados na sua atuação profissional (BRASIL, 2003).

Nesse panorama, a EaD apresenta perspectivas interessantes. Além de facilitar o acesso à educação, formando um maior número de profissionais, pode, por suas características próprias de ensino/aprendizagem, formar profissionais diferenciados, que trarão novas ideias e modos de atuar na área educacional (NEDER, 2006).

No entanto, para que essas perspectivas se concretizem, é preciso solucionar um problema que tem sido frequente na $\mathrm{EaD}$ : a evasão. Esta pode ser entendida como a saída, sem concluir, de um estudante que iniciou o curso. Esse problema pode comprometer os objetivos da Educação a Distância, tornando baixo o número de profissionais formados, não justificando o investimento nessa modalidade.

Sendo assim, é necessária a realização de estudos que elucidem os motivos da evasão dos estudantes, pois desse modo será possível desenvolver estratégias 
que minimizem o abandono. Por isso, este trabalho tem o objetivo de estudar os motivos de evasão no curso de Licenciatura em Ciências Biológicas oferecido pela Universidade do Estado do Rio de Janeiro (UERJ) no polo EaD do município de Nova Friburgo, situado na Região Serrana do Estado do Rio de Janeiro, que faz parte do Consórcio Centro de Educação Superior a Distância do Estado do Rio de Janeiro (Cederj) e do Sistema Universidade Aberta do Brasil (UAB).

Com o intuito de alcançar o objetivo proposto, será apresentada uma breve revisão da literatura sobre essa temática. Posteriormente, os resultados do estudo exploratório sobre os motivos da evasão no curso de Licenciatura em Ciências Biológicas do polo EaD de Nova Friburgo serão discutidos levando em conta a análise das entrevistas realizadas com 30 ex-alunos do curso.

\section{Evasão em Educação a Distância}

Existem diversas definições para evasão. Um trabalho que tenha por objetivo estudá-la deve defini-la, pois o conceito utilizado pode influenciar nos resultados obtidos (ALMEIDA, 2008). Neste trabalho será considerada evasão quando o aluno se matricula no curso e, durante alguma etapa, desiste de concluí-lo, mesmo sem ter cursado nenhuma disciplina.

Faria, Alcântara e Vasco (2008, p. 1) destacam que "a evasão universitária tem se caracterizado como uma realidade recorrente no âmbito do ensino de graduação em várias partes do mundo". As autoras verificam que, no caso dos cursos a distância, os índices de evasão são expressivamente maiores do que nos cursos presenciais, pois, ao compararem os índices de evasão em disciplinas de cursos superiores simultaneamente oferecidos presencialmente e a distância, encontram índices maiores na modalidade a distância em todas as disciplinas analisadas. Outro resultado importante é quanto aos motivos que levam os alunos a desistir dos cursos. As autoras citadas destacam que o principal motivo de desistência nos cursos presenciais são fatores socioeconômicos; nos cursos a distância, a esses fatores se somam diversos outros, com igual ou maior importância.
Os cursos a distância apresentam diversos aspectos que propiciam flexibilidade aos alunos, mas também possuem desafios a serem superados, como a dificuldade para acompanhar um cronograma de estudos, problemas com a tecnologia necessária para um melhor aproveitamento e a necessidade de autonomia do estudante para coordenar sua aprendizagem. Isso pode levar os alunos a desistir do curso sem o concluir. Almeida (2008), ao analisar os motivos de desistência de um curso EaD de especialização, classifica em cinco categorias principais os alunos que abandonam o curso. A primeira categoria refere-se aos fatores situacionais que ocorrem durante o curso e que podem levar o aluno à evasão. Entre esses fatores a autora cita a falta de apoio no trabalho, curso simultâneo, problemas familiares e falecimento de familiares, entre outros. É nesses momentos de tensão que se torna relevante outro fator importante na persistência ou não dos alunos: as características pessoais. Moorey e Kearsley (2008) destacam que os alunos mais propensos a se sair bem em cursos a distância são aqueles menos influenciados pelo ambiente que os rodeia. Os autores acreditam haver ainda relação entre o sucesso e a introversão-extroversão dos alunos, seu perfil e sua personalidade.

A segunda categoria destacada por Almeida (2008) é a falta de apoio acadêmico. Nela estão aqueles alunos que não consideram adequado o apoio acadêmico dado pelo curso. Nesse ponto, as tutorias presenciais desempenham papel fundamental. Flinte, Grenha e Macedo (2008) ressaltam que, no caso dos cursos de graduação do Cederj,

\footnotetext{
para os primeiros períodos, a tutoria presencial é considerada extremamente importante, como forma de orientação dos alunos em seus estudos e estímulo para formação de grupos de estudos, ajudando-os na fase de adaptação ao sistema semipresencial. (FLINTE; GRENHA; MACEDO, 2008, p. 4).
}

As autoras analisam o desempenho dos alunos com relação a três disciplinas do curso de Licenciatura em Ciências Biológicas e encontram uma relação positiva entre a frequência às tutorias e as notas nas disciplinas. 
Dando prosseguimento, Almeida (2008) encontra a terceira categoria: a das pessoas que encontram problemas em usar a tecnologia oferecida pelo curso. Esse grupo inclui tanto aqueles que não possuem acesso à internet ou computador quanto aqueles que, mesmo tendo acesso, não conseguem utilizar os recursos disponíveis. Levando em conta a importância da tecnologia e especialmente do computador para a aprendizagem a distância, não saber usá-lo pode ser um fator limitador para o estudante. Maia e Meirelles (2005) encontram em seu trabalho relação também entre a tecnologia utilizada no curso e o índice de evasão.

Ainda no trabalho de Almeida (2008) uma quarta categoria é identificada: a dos alunos que reclamam da falta de apoio administrativo. Nessa categoria são relacionados aqueles alunos que abandonam o curso por falta de material didático, que pode ser entregue fora do prazo ou sem algumas partes. Também podem ser incluídos nessa categoria alunos insatisfeitos com cronogramas mal elaborados ou que não sejam cumpridos pelo curso.

A quinta categoria identificada por Almeida (2008) é a da sobrecarga de trabalho. Nessa categoria estão agrupados aqueles que, por terem excesso de carga horária no trabalho, não conseguem acompanhar o curso e por isso acabam desistindo. A autora relata que muitos alunos de cursos a distância possuem carga horária de até 13 horas diárias, o que torna muito complicado conseguir conciliar as atividades do trabalho com o estudo. Deve ser ressaltada aqui a importância de ter tempo para realizar as atividades propostas pelo curso e estudar diariamente. Muitos alunos podem entrar no curso pensando que terão que estudar menos que num curso presencial, por isso não planejam um horário para estudar. O confronto com a realidade do curso pode levar o aluno a abandoná-lo.

Corrêa e Lacerda (2011), ao analisar, por meio de entrevistas com alunos e tutores, os motivos de evasão nos cursos de Licenciatura em Ciências Biológicas e em Pedagogia do polo EaD de Nova Friburgo, também encontraram como fatores que influenciam na desistência os problemas com a tecnologia proble- mas de ordem pessoal e sobrecarga de trabalho. Além disso, identificaram, por parte dos alunos, expectativas incorretas com relação à Educação a Distância e dificuldades com matérias que exigem maior esforço $e$ conhecimento prévio do aluno como possíveis fatores que influenciam nos índices de evasão.

\section{O caso do curso de Licenciatura em Ciên- cias Biológicas do polo EaD de Nova Friburgo}

\subsection{Metodologia adotada}

Com o objetivo de conhecer o número de alunos evadidos no curso de Licenciatura em Ciências Biológicas do polo EaD de Nova Friburgo, foi realizada a análise documental dos dados relativos às dez primeiras turmas, matriculadas nesse curso no período de 2006 a 2011: a turma que ingressou no primeiro semestre de 2006 (2006/1), a turma do primeiro semestre de 2007 (2007/1), a turma do segundo semestre de 2007 (2007/2) e assim por diante até a turma do primeiro semestre de 2011 (2011/1). Esses dados foram obtidos no sistema acadêmico do Cederj no segundo semestre de 2012.

Para conhecer os motivos de evasão, foram realizadas entrevistas por telefone com 30 ex-alunos, três representantes de cada uma das dez turmas, de 2006/1 a 2011/1. Foi perguntado o motivo de deixarem o curso e o período em que ocorreu a desistência. As respostas foram anotadas para posterior análise.

\subsection{Resultados e discussões}

Verificamos que, dos 450 alunos matriculados nas dez turmas analisadas, 195 tiveram sua matrícula cancelada, resultando em um índice de evasão de 43,3\%.

Sobre esse resultado, alguns pontos devem ser destacados: como a matriz curricular utilizada no curso é de cinco anos, no momento da realização deste trabalho, apenas as três primeiras turmas (2006/1, 2007/1 e 2007/2) possuíam alunos forma- 
dos, e todas as turmas tinham estudantes em curso. Outra informação relevante é que o cancelamento de matrícula pode ser realizado por solicitação do aluno ou de modo automático, que ocorre apenas quando o aluno não se matricula em nenhuma matéria durante quatro períodos seguidos (Cederj, s/d). Dessa forma, as duas turmas mais recentes (2010/2 e 2011/1) apresentam apenas dados de evasão relativos aos estudantes que pediram o desligamento do curso (representados em verde na Figura 1), enquanto nas oito primeiras turmas já são considerados os dados de evasão de estudantes que pediram desligamento do curso e dos que tiveram suas matrículas canceladas automaticamente (representados em azul na Figura 1). Isso quer dizer que os dados relativos à evasão não são estáveis; por isso, os índices podem se modificar ao longo do tempo. Entretanto, conforme discutido em diversos trabalhos, por exemplo, Jorge e colaboradores (2010); Oliveira, Cavalcanti e Gonçalves (2012) e como será reiterado neste estudo, a maioria dos alunos que eva- dem em um curso de Educação a Distância faz isso nos períodos iniciais. Com essas ressalvas, podemos dizer que, no momento, esse resultado é menor do que o apontado por Maia e Meirelles (2004) para a Educação a Distância: 68\% de evasão. No entanto, se tomarmos como grupo amostral apenas as quatro primeiras turmas, que estão atualmente cursando períodos mais avançados, o índice é próximo a isso: $60,5 \%$.

Quando analisada nas diferentes turmas, de 2006/1 a 2010/1, percebemos na Figura 1 que a evasão tem apresentado tendência de diminuição, sobretudo a partir de 2008/1. A turma que parece fugir a essa tendência é a turma 2010/1. Sobre isso é importante observar que, no primeiro semestre de 2010, a Universidade Federal Fluminense (UFF) iniciou no município de Nova Friburgo as atividades dos cursos de graduação em Biomedicina e Fonoaudiologia, dois cursos que, como será relatado mais adiante, são o destino de alguns alunos que evadem para o ingresso em outra graduação.

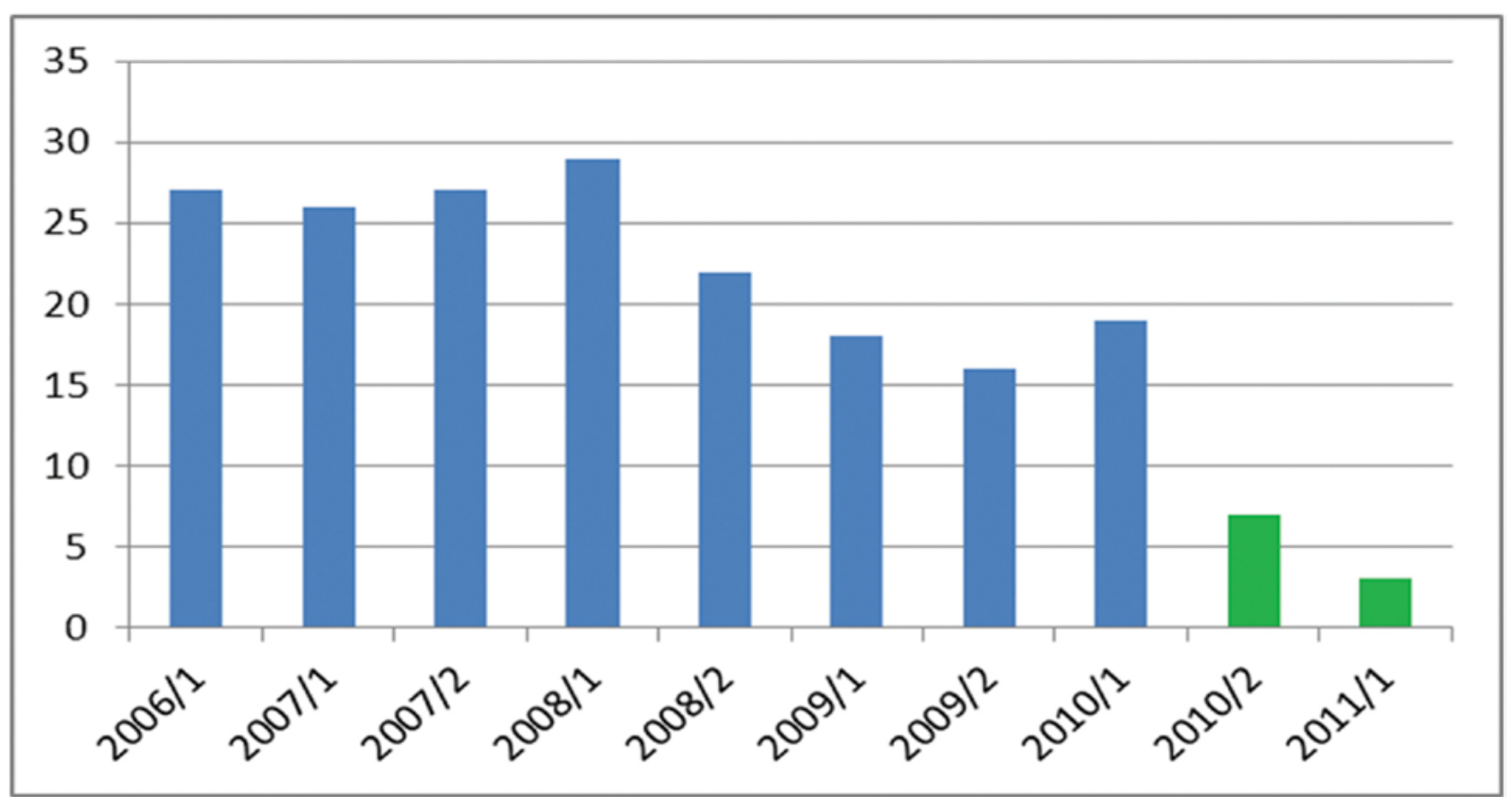

Figura 1: Número de alunos evadidos por turma (de um total de 45). 
Podemos também observar que existe tendência de a evasão ser maior nas turmas do primeiro semestre do que nas turmas do segundo. Isso provavelmente acontece porque, no início do ano, a grande maioria das universidades faz seleção para o ingresso em seus cursos e, como será discutido adiante, um dos principais motivos de evasão no curso de Licenciatura em Ciências Biológicas do polo EaD de Nova Friburgo é o ingresso em outro curso superior.

É importante frisar que o Cederj passou a disponibilizar para os alunos calouros, desde 2008/2, a disciplina Seminários em Educação a Distância, que, segundo o guia da disciplina, procura instruir os alunos sobre os métodos de estudos em $\mathrm{EaD}$, inseri-los em um grupo de estudos e familiarizá-los com um ambiente virtual de aprendizagem. Além dessa ação, têm sido realizadas mudanças na matriz curricular que procuram organizar disciplinas preparatórias nos períodos iniciais, a fim de diminuir o grau de dificuldade do curso. Verificamos, ainda, que o Cederj organiza, desde 2011/2, um programa de acolhimento dos calouros que procura orientá-los quanto aos métodos da $\mathrm{EaD} e$ quanto ao modo de estudar mais adequado ao seu perfil. Isso é feito por meio da ação de um tutor coordenador que acompanha a evolução das atividades avaliativas dos estudantes durante todo o primeiro período do curso.

Podemos perceber, por esses exemplos, que algumas ações direcionadas aos estudantes do primeiro período estão sendo realizadas com o objetivo de diminuir os índices de evasão. Contudo, para que sejam adotados métodos eficientes, é necessário que se conheçam os motivos que levam os alunos a abandonar o curso. Por isso, neste estudo exploratório, foram realizadas entrevistas que procuram apontar os motivos que levam os alunos a evadir do curso de Licenciatura em Ciências Biológicas do polo EaD de Nova Friburgo.

$\mathrm{O}$ questionamento sobre em que período ocorreu a desistência do curso produziu um resultado bem claro: a desistência acontece principalmente nos períodos iniciais. Alguns alunos, principalmente aqueles com matrículas mais antigas, não conseguiram responder exatamente em que período a desistência tinha ocorrido, ficando em dúvida entre dois períodos. Por isso, separamos os alunos em dois grupos: aqueles que desistiram até o terceiro período e aqueles que desistiram a partir daí. Dos trinta ex-alunos contatados, 27 (90\%) declararam ter desistido do curso quando cursavam até o terceiro período, enquanto apenas três ex-alunos $(10 \%)$ desistiram em períodos posteriores. Entre estes últimos, um desistiu no quarto período, um desistiu no quinto e um no sexto. Não foram registradas desistências do sexto período em diante.

Esses resultados confirmam outros trabalhos. Jorge e colaboradores (2010), por exemplo, estudaram o perfil dos alunos evadidos de um curso de Educação a Distância. Nesse estudo, encontraram que $70 \%$ dos estudantes abandonam o curso ainda no primeiro semestre. Daí em diante a evasão diminui progressivamente. Oliveira, Cavalcanti $e$ Gonçalves (2012) corroboram esses resultados: em seu trabalho, encontraram maior número de desistências nos períodos iniciais.

$\mathrm{O}$ questionamento sobre os motivos de desistência do curso nos levou a diferentes categorias de respostas, como demonstrado na Figura 2. 


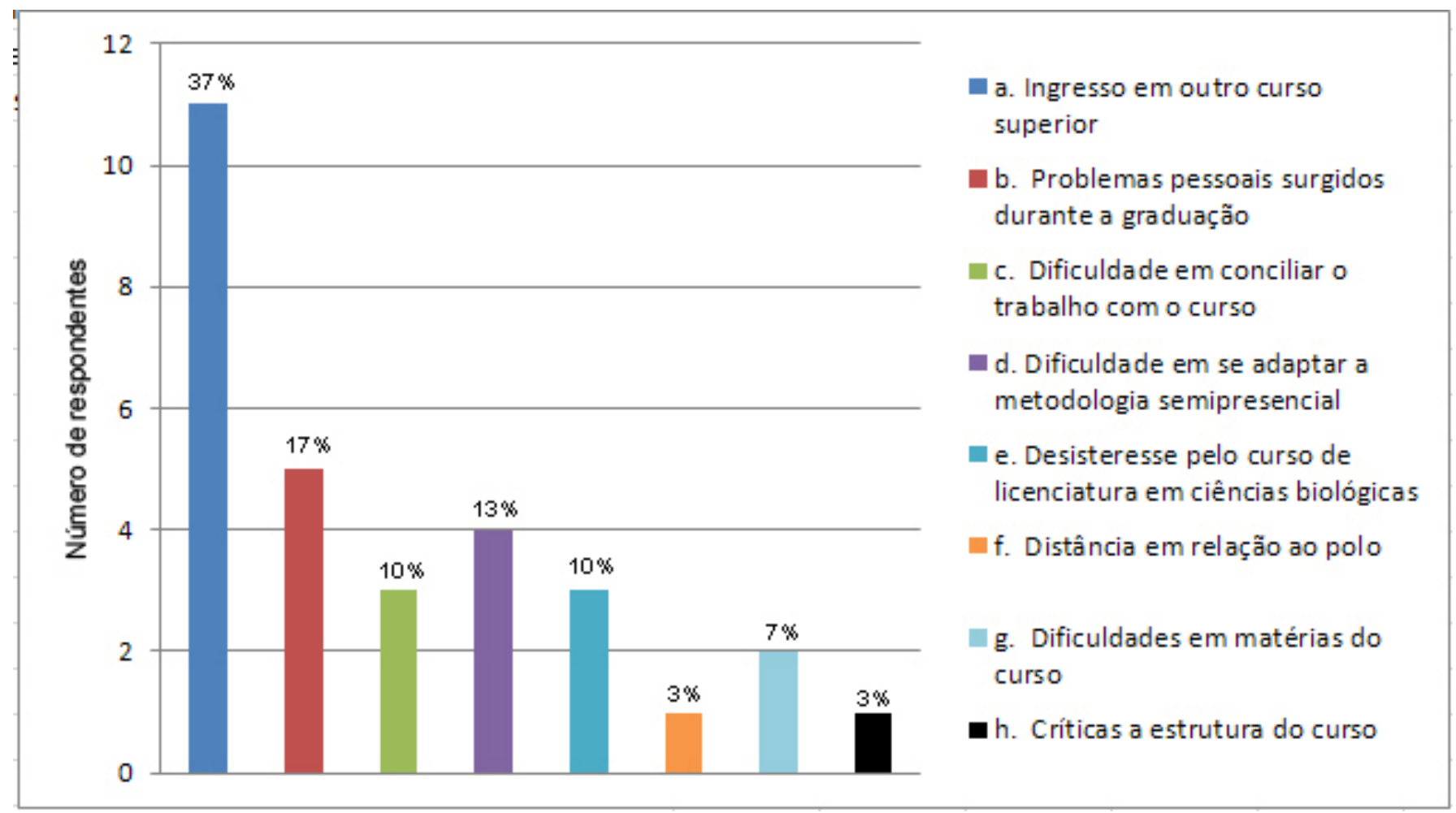

Figura 2: Principal motivo que levou os ex-alunos a evadir.

O motivo mais citado foi abandono para ingresso em outro curso superior. A esse se somam problemas pessoais ocorridos durante o curso, dificuldade em conciliar o trabalho com os estudos, dificuldade de se adaptar à metodologia do ensino semipresencial, dificuldade com algumas disciplinas do curso, distância em relação ao polo, falta de interesse pelo curso de Licenciatura em Ciências Biológicas e críticas à estrutura do curso. É importante destacar que alguns alunos citaram mais de um motivo, mostrando que, muitas vezes, mais de um fator contribui para a desistência. Dessa forma, para a divisão em categorias, foi considerado apenas o motivo principal que levou o estudante a evadir.

A seguir, será detalhada cada uma destas categorias.

\section{a) Evasão para o ingresso em outro curso superior}

O principal fator que levou os alunos entrevistados a deixar o curso foi o ingresso em outro curso superior. Esse motivo foi citado por onze ex-alunos $(36,5 \%)$. Esses ex-alunos, em sua maioria, apresen- tam perfil bem claro: normalmente são aprovados no vestibular de mais de uma instituição e, após realizar a matrícula, ainda no primeiro semestre, acabam optando pelo curso presencial. Esse foi o caso de nove dos onze alunos incluídos nessa categoria. Como padrão, não chegam nem a iniciar efetivamente o curso ou, quando iniciam, não fazem nem a primeira prova. Por exemplo, o ex-aluno 1, da turma 2009/1 comenta:

\footnotetext{
Nem cheguei a ser aluno. Me inscrevi no Cederj, mas tinha passado também para Engenharia Mecânica na UERJ. Fiz minha matrícula, mas nem cheguei a pegar nenhum livro, ler nenhuma aula, fazer nenhuma prova nem nada. Desisti antes mesmo de iniciar o curso, logo no meio do semestre já tinha pedido o cancelamento da matrícula.
}

Entre os outros oito ex-alunos que desistiram logo no primeiro período e estão incluídos nessa categoria, também foi comum ouvir frases como "não cheguei a fazer nenhuma prova", "preferi o curso presencial" e "o outro curso me interessava mais". Cinco entrevistados optaram por cursos da área biomédica 
oferecidos pela UFF em Nova Friburgo. Além dos nove casos de ex-alunos que deixaram o curso de Licenciatura em Ciências Biológicas no primeiro período para ingressar em cursos presenciais, dois abandonaram em períodos posteriores pelo mesmo motivo. Isso demonstra que a opção por outro curso superior também pode ser estimulada pela dificuldade em se adaptar à modalidade semipresencial (como será discutido no item d).

\section{b) Problemas pessoais surgidos durante a gra- duação}

Os problemas surgidos durante a graduação foram apontados como determinantes para a desistência por cinco ex-alunos (16,7\%). É possível perceber, nessa categoria, como a intenção de concluir e a personalidade do aluno, discutidas por Moorey e Kearsley (2008), têm relevante importância para determinar se o aluno continuará ou não no curso quando surge um problema. Por exemplo, destacamos o que relatou a ex-aluna 5, da turma 2006/1:

\footnotetext{
Logo que entrei no curso, tive que fazer uma cirurgia. Isso fez com que eu tivesse que ficar seis meses afastada dos estudos. Quando voltei, não consegui mais acompanhar o ritmo. Também já tenho outras duas graduações, por isso não estava tão interessada em concluir mais essa. Isso acabou me desanimando.
}

Outro respondente incluído nessa categoria (ex-aluno 23, da turma 2008/1) declarou estar indo bem; entretanto, no quarto período começou a passar por dificuldades financeiras. Isso fez com que tivesse que trabalhar mais e, como consequência, não conseguiu mais estudar como fazia antes; acabou desanimando e abandonando o curso.

Realmente a sobrecarga de trabalho dificulta os estudos em um curso que exige carga horária extensa dos alunos. Além disso, por se tratar de um curso semipresencial, os alunos precisam participar de algumas atividades obrigatórias, no polo o que novamente pode entrar em conflito com as atividades do trabalho. Isso nos leva à próxima categoria.

\section{c) Dificuldade para conciliar o trabalho com as atividades do curso}

A dificuldade em conciliar o curso com o trabalho foi apontada como principal motivo de desistência por três alunos (10\%). Também aqui aparece a motivação para terminar o curso como fator que pode influenciar ou não na permanência. Isso pode ser percebido na fala do ex-aluno 8, da turma 2007/1, desistente no $5^{\circ}$ período: mais uma vez a anterior conclusão de outro curso superior interferiu na evasão.

\footnotetext{
O motivo da minha desistência foi a incompatibilidade com o trabalho. Não consegui conciliá-lo com o curso. Eu já possuía um curso superior. Quando abriu concurso na minha área eu fiz e fui aprovado. A partir daí aumentou muito minha carga horária.
}

A dificuldade de acompanhar as tutorias e as outras atividades obrigatórias é ressaltada pelo ex-aluno 9, da turma 2009/2.

\footnotetext{
As tutorias eram nos finais de semana, exatamente os dias em que tinha que dar plantão no trabalho. Mesmo assim fui levando, mas comecei também a perder práticas e provas, o que acabou fazendo com que eu desistisse. Eu era novo no trabalho, tinha sido transferido há pouco tempo de Teresópolis para Friburgo, por isso não podia faltar. Hoje me arrependo, pois está fazendo falta no meu trabalho atual.
}

Mesmo abandonando o curso, alguns relataram gostar de sua metodologia. Entretanto, alguns ex-alunos abandonaram a licenciatura exatamente por não se adaptarem à metodologia semipresencial, como será discutido na próxima categoria.

\section{d) Dificuldade em se adaptar à metodologia semipresencial}

A dificuldade para se adaptar à metodologia do curso semipresencial foi apontada como principal fator de desistência por quatro ex-alunos (13,3\%). Três deles lembram que é difícil se manter motivado estudando sozinho. Percebe-se em suas 
falas que não consideram as tutorias presenciais como método importante para organizar os estudos e encontrar colegas. Por exemplo, o ex-aluno 11, da turma 2006/1, diz: "Não me habituei aos métodos do Cederj; tenho muita dificuldade em estudar sozinho". A ex-aluna 12 (turma 2007/2) diz que encontrava dificuldades em diversas matérias do primeiro período e que essa dificuldade era devida ao fato de o curso ser semipresencial, pois ela estava habituada a ter aulas, encontrar colegas e ver o professor expondo o conteúdo. Com esse método, não conseguia acompanhar o cronograma. O ex-aluno 13 (turma 2009/2) é bem objetivo: "Eu saí do curso pelo fato de ele ser semipresencial. Estava com mau desempenho nas provas, cheguei a cursar um período, no segundo desisti".

O ex-aluno 14, da turma 2007/2, aponta como principal motivo de desistência, além do fato de o curso ser semipresencial, o excesso de obrigações, pois o que esperava era um curso totalmente a distância:

\footnotetext{
Não gostei do sistema do curso. Pensei que fosse fazer um curso a distância, mas vi que teria mais obrigações que em um curso presencial. Todo final de semana tinha provas, aulas práticas, necessidade de ir ao polo entregar trabalhos e outras atividades. Esperava um curso para adultos, em que fosse capaz de gerenciar minha própria aprendizagem, mas encontrei um sistema de tutelagem, em nada diferente de uma escola normal. Não gostei do sistema. Desisti logo no final do primeiro período.
}

Isso quer dizer que alguns alunos se matriculam no curso com uma expectativa diferente da proposta metodológica do Cederj, o que reforça a necessidade de uma orientação intensa dos alunos calouros no que se refere à metodologia do curso.

\section{e) Desinteresse pelo curso de Ciências Bio- lógicas}

Estão incluídos nesta categoria os alunos que entraram para o curso de Biologia mas desejavam cursar outra graduação. Esses alunos apontam que não se adaptaram ao curso pois, na verdade, gostariam de cursar outro, sendo este o principal motivo de sua desistência. Esse foi o caso de três ex-alunos (10\%) do grupo pesquisado.

Como exemplo, registramos o depoimento do ex-aluno 15, da turma 2008/1:

\begin{abstract}
Entrei para o curso de Biologia porque não tinha a opção que queria em uma região próxima ao local onde moro. Queria fazer Administração. Minha desistência não teve nenhuma relação com a estrutura do curso, pois gosto de sua metodologia de ensino. Foi uma incompatibilidade com o curso de Biologia mesmo. Vou no futuro prestar vestibular para Administração no próprio Cederj.
\end{abstract}

A ex-aluna 17, da turma 2007/1, desejava cursar uma licenciatura. Entretanto, achou complicadas as matérias encontradas no curso de Ciências Biológicas:

Entrei para o curso porque queria ser professora, dar aulas. Só que não gostei de Biologia. Tinha algumas matérias muito difíceis, muita Química. Descobri que o que queria era Pedagogia. Cheguei a me inscrever para o vestibular de 2012/2, só que não pude ir no dia da prova.

Assim, percebemos como a dificuldade em matérias do curso também pode influenciar na evasão, como será visto no item g.

\section{f) Distância em relação ao polo}

A distância do polo para o local de moradia foi citada como principal motivo de desistência apenas pela ex-aluna 18 , da turma $2008 / 2$, o que corresponde a 3,3\% dos entrevistados:

\footnotetext{
Morava em Santa Maria Madalena, eram $90 \mathrm{~km}$ de distância, duas horas de ônibus, uma hora de carro. Por isso, ficava impossivel acompanhar as tutorias, que considerava muito importantes... Estava com dificuldades em Química; essa matéria, pelo menos no tempo em que cursei o Ensino Médio, apresentava muitas deficiências nas escolas. Fui pegando as matérias em que era possível estudar sozinha, mas fui deixando Bioquímica e Elementos de Química Geral, até que no terceiro período ficou impossível acompanhar e desisti. Infelizmente, ficava muito caro para me deslocar até o polo. Voltaria a cursar se fosse mais perto.
} 
Essa aluna ressalta a importância da tutoria presencial para que tenha bom desempenho; entretanto, em nenhum momento lembra da tutoria a distância como ferramenta que poderia diminuir suas dificuldades. Também comenta a dificuldade encontrada na disciplina Química como um dos motivos que a levou a desistir do curso. Realmente, as matérias que envolvem Química foram as mais citadas quando os respondentes lembravam as dificuldades encontradas em disciplinas do curso. Esse é o assunto do próximo item.

\section{g) Dificuldades em matérias do curso}

Dois ex-alunos $(6,7 \%)$ citaram a dificuldade encontrada em matérias no curso como principal motivo para sua desistência. É interessante perceber, porém, que essa dificuldade foi lembrada como motivo secundário por mais duas ex-alunas (ex-aluna 18 e ex-aluna 17), cujos depoimentos já foram transcritos neste trabalho. Parece que a dificuldade com as matérias surgem para esses alunos como motivo resultante de alguma outra circunstância. Para a ex-aluna 18, por exemplo, a dificuldade vinha de não poder acompanhar as sessões de tutoria por causa da distância. É possível perceber também que, mesmo quando a dificuldade com alguma matéria é o principal motivo para a desistência, são citados também outros motivos. Como no caso da ex-aluna 19, da turma 2008/2:

Abandonei o curso porque achei que fosse complicar muito. O primeiro e o segundo períodos foram complicados. Fiz várias AP3s e fui reprovada em algumas matérias. Meus amigos que também fazem o curso me disseram que ainda iria complicar muito, que viriam matérias com Matemática, Química e Física. Sou mãe de três filhos, não teria muito tempo para estudar. Esperava um curso mais "light".

Esse caso reafirma a teoria apresentada por Moorey e Kearsley (2008), de que os alunos menos influenciados pelo ambiente são mais propensos a ter bons resultados na EaD. A ex-aluna 19 citou como principal motivo para sua desistência o receio de que o curso pudesse ficar mais complicado, medo esse despertado através de relatos de amigos do curso. Além disso e da dificuldade encontrada nas matérias, cita um motivo pessoal, a necessidade de cuidar dos filhos, como fator que a levou a desistir.

Enquanto isso, a ex-aluna 20, da turma 2007/2, não encontrava dificuldade somente nas matérias que envolvem a Química e a Física, mas também em outras:

Tive dificuldades em todas as matérias do primeiro período. Achei bem difícil o curso. Isso acabou me levando a desistir. Talvez fosse mais fácil se tivesse tempo para ir às tutorias, mas o horário era complicado para mim, trabalhava à noite. Isso fez complicar bastante.

Neste depoimento novamente é lembrada a importância da tutoria presencial para esclarecer dúvidas a respeito de matérias mais complicadas. Além disso, há a conjugação de outro motivo, a dificuldade em conciliar o trabalho com o curso, como fator de desistência. Essa ex-aluna também não valorizou, em sua fala, a tutoria a distância como ferramenta que poderia auxiliar na resolução de dúvidas.

\section{h) Críticas à estrutura do curso}

Apenas um aluno $(3,3 \%)$ relatou ter abandonado o curso pela falta de qualidade do material didático $e$ má organização. Foi o ex-aluno 22, da turma 2008/1.

Achei o curso desorganizado, o material didático ruim (muitos erros); não atendeu em nada minhas expectativas. Cursei dois períodos inteiros; depois, já decepcionado, ainda me inscrevi para algumas matérias do terceiro período, quando acabei abandonando.

O número de reclamações sobre a estrutura do curso encontrado neste estudo é bem pequeno em relação ao relatado em outros trabalhos. Almeida (2008), por exemplo, encontra alunos que reclamam da falta de apoio acadêmico e falta de apoio administrativo em porcentuais de $46 \%$ e $26 \%$, respectivamente. Lacerda (2010) justifica que a estrutura oferecida aos estudantes nos polos regionais minimiza o surgimento de problemas como a falta 
de apoio acadêmico e administrativo nos cursos de graduação oferecidos pelo Cederj. A declaração do ex-aluno 22 parece não estar em consonância com outros relatos de estudantes do curso de Licenciatura em Ciências Biológicas, para os quais a qualidade do material didático é o ponto forte do curso (CORRÊA; LACERDA, 2011).

\section{Considerações finais}

Pelo levantamento bibliográfico realizado foi possível perceber que existem diversos fatores que podem levar à evasão dos estudantes na EaD. Esses fatores podem estar relacionados tanto às características dos estudantes quanto ao ambiente externo.

De fato, existem desafios a serem superados na formação inicial de professores. Muitos fatores contribuem para que um pequeno número de profissionais seja formado, tornando ainda mais importante os estudos que elucidem os motivos de os alunos abandonarem um curso de licenciatura, pois só assim será possível combater esse fenômeno. Acreditamos ainda, como Neder (2006), que a EaD pode contribuir para formar profissionais diferenciados, com novas ideias para enfrentar os desafios da profissão docente.

No estudo exploratório realizado no polo EaD de Nova Friburgo, ao analisar os motivos de evasão no curso de Licenciatura em Ciências Biológicas, verificamos que a desistência ocorre principalmente nos períodos iniciais e que alguns dos fatores que levam a desistência nem sempre estão sujeitos ao controle da instituição de ensino. Esse é o caso, por exemplo, dos alunos que se inscrevem em mais de um curso e depois desistem de um deles. A evasão para o ingresso em outro curso superior foi o principal motivo citado pelos entrevistados para justificar a desistência do curso. Temos ainda aqueles casos em que a evasão não está ligada diretamente a essa modalidade de ensino, mas sim à incompatibilidade com o curso de Li- cenciatura em Ciências Biológicas. Há respondentes que declaram estar dispostos a optar de novo pela Educação a Distância em um outro curso de graduação.

Outros fatores recorrentes que levam à evasão são: dificuldade em conciliar o trabalho com o curso e problemas pessoais surgidos durante a graduação. É difícil para os alunos manter-se sem adversidades durante o tempo bastante longo da graduação. Quando os problemas surgem, a intenção de concluir é um fator relevante, pois um aluno que queira chegar ao fim do curso lutará para superar os desafios encontrados.

É importante ressaltar o papel da tutoria a distância, muitas vezes deixado em segundo plano pelos alunos. Essa ferramenta pode diminuir as dificuldades daqueles alunos que alegam não ter horário disponível para acompanhar a tutoria presencial. Também poderia ajudar aqueles que residem longe do polo.

A dificuldade para conciliar o trabalho com as atividades do curso, seja pela incompatibilidade do horário das atividades presenciais obrigatórias ou por "não sobrar tempo para estudar", é difícil de ser superada. Por ser um curso semipresencial o aluno realmente terá que se deslocar até o polo para realizar algumas atividades, algo nem sempre entendido por um aluno que espera um curso totalmente a distância. O problema da falta de tempo para estudar é ainda mais complicado de ser resolvido. Afinal, o curso de graduação exige grande carga horária semanal de estudos, nem sempre compatível com quem possui carga horária extensa no trabalho. Entretanto, é possível que, durante o curso, em períodos em que o aluno está com menos tempo disponível, ele se inscreva em um menor número de matérias, o que é permitido, já que o curso é oferecido em regime de crédito, tal qual o curso presencial. Assim, é possível perceber a importância do programa de acompanhamento dos calouros, que vem sendo desenvolvido desde 2011 e que procura auxiliar os alunos ingressantes 
a, entre outras coisas, escolher o número de matérias compatível com seu tempo disponível.

Quanto às dificuldades encontradas para se adaptar à metodologia semipresencial, às dificuldades com matérias específicas do curso e às críticas à estrutura do curso, verificamos que a instituição já tem tomado algumas medidas, como a reformulação da matriz curricular e a introdução da disciplina Seminários em Educação a Distância, que procura orientar os alunos calouros nos métodos de estudo semipresencial e aproximá-los dos colegas. Esse esforço pode já estar dando resultados, pois verificamos tendência de diminuição de evasão nas turmas a partir do primeiro semestre de 2008, quando algumas dessas ações começaram a ser implementadas. Entretanto, sugerimos que as turmas de Licenciatura em Ciências Biológicas continuem a ser acompanhadas e que este estudo seja ampliado para outros cursos e em outros polos de educação a distância.

\section{Referências}

ALMEIDA, O. C. S. Evasão em cursos a distância: análise dos motivos de desistência. 2008. Disponível em: < www.abed.org.br/congresso2008/tc/552008112738PM.pdf > . Acesso em: 17 set. 2012.

BRASIL. Instituto Nacional de Estudos e Pesquisas Educacionais. Estatísticas dos professores no Brasil. Brasília: MEC/SEF, 2003.

CEDERJ. Curso de Licenciatura em Ciências Biológicas. Projeto político-pedagógico. Rio de Janeiro: Universidade do Estado do Rio de Janeiro, s/d.

CARVALHO, A. M. P.; GIL-PÉREZ, D. Formação de professores de Ciências. $5^{\mathrm{a}}$ ed. São Paulo: Cortez, 2001. Coleção Questões da Época, v.26.

CORRÊA, P. S.; LACERDA, F. K. D. EaD e evasão no polo de Nova Friburgo: identificando causas e propondo soluções. In: VIII Congresso Brasileiro de Ensino Superior a Distância, 2011, Ouro Preto/MG.

FARIA, M. O. F; ALCANTARA, V. M.; VASCO, C. G. Índice e causa de evasão na modalidade a distância em cursos de graduação: estudo de caso. In: VI Congresso Internacional de Educação Superior, 2008, Havana.

FERREIRA, R. Entre o sagrado e o profano: o papel social do professor. $3^{\text {a }}$ ed. Rio de Janeiro: Quartet, 2001.

FLINTE, V.; GRENHA, V.; MACEDO, M. V. Frequência dos alunos nas tutorias presenciais e seu desempenho acadêmico em disciplinas de primeiro período do curso de Licenciatura em Ciências Biológicas, Cederj. In: V Congresso Brasileiro de Ensino Superior a Distância, 2008, Gramado/RS.

JORGE, B. G. et al. Evasão na educação a distância: um estudo sobre a evasão em uma instituição de ensino superior. 2010. Disponível em: <http://www.abed.org.br/congresso2010/cd/252010220450.pdf > . Acesso em: 22 dez. 2012.

LACERDA, F. K. D. Ações afirmativas e EaD: um estudo de caso. Revista Tessituras, v. 2, n. 2, p. 18, nov. 2010. Disponível em: < www.revistatessituras.com.br> . Acesso em: 28 nov. 2012.

MAIA, M. C.; MEIRELLES, F. S. Tecnologias de informação e comunicação e os índices de evasão nos cursos a distância. 2005. Disponível em: < http://www.abed.org.br/congresso2005/por/pdf/181tcc3.pdf $>$. Acesso em: 24 set. 2012. 
MOOREY, M.; KEARSLEY, G. Educação a distância: uma visão integrada. São Paulo: Cengage Learning, 2008.

NEDER, M. L. C. Educação a distância e sua contribuição na mudança de paradigmas educacionais na formação de professores. In: Desafios da educação a distância na formação de professores. Brasília: MEC/Secretaria de Educação a Distância, 2006. p. 79-85.

OLIVEIRA, A. C.; CAVALCANTE, I. F.; GONÇALVES, R. S. O processo de evasão (ou desistência) no curso de Licenciatura em Letras-Espanhol ofertado pelo campus EaD - IFRN: causas possíveis. In: Simpósio Internacional de Educação a Distância, 2012, São Carlos/SC.

SANTOS, E. O. Educação online pra além da EaD: um fenômeno da cibercultura. In: X Congresso Internacional Galego-Português de Psicopedagogia. Braga: Universidade do Minho, 2009.

SARAIVA, T. Educação a Distância no Brasil: lições da história. Em aberto, v. 16, n. 70, p. 17-27, 1996. 